\title{
Economic Designing of PV/FC/Wind Hybrid System Considering Components Availability
}

\author{
Saber Arabi No wdeh,Mahdi Hajibeigy \\ Sama Technical and Vocational Training College, Islamic A zad University, Urmia Branch, Urmia, Iran. \\ sa_arabi@yahoo.com \\ mehdihb2019@gmail.com
}

\begin{abstract}
This paper presents an Optimization Sizing of a stand-alone PV/FC/Wind Hybrid System (PFWHS) to optimize the sizes of components of PFWHS. Based on PSO algorithm, one optimal sizing method was developed to determine the optimal configuration of system that can achieve the load required power supply probability (Reliability) with a minimum overall cost of energy (OCE).PFWHS costs involve investments, operation and maintenance as well as loss of load costs. The applied wind and radiation datasets belong to northwest region (Jolfa, latitude: 38_56, longitude: 45_37, altitude: 710, m) of Iran. In this paper the impact of availability of PFWHS components is investigated on optimal sizing. So, to investigating the impact of component availability rate on PFWHS costs and reliability due to failure and repair rate of PFWHS components and uncertainty in wind speed and solar irradiance, two scenarios are considered. In first scenario the availability of all components is considered 1 and in second scenario isn't considered 1 because of failure and repair rate of components and uncertainty in wind speed and solar irradiance. Obtained results prove that while the overall cost of energy is optimized, the reliability indices are within a satisfactory bound with regard to the reliability standards. Also the results indicate that considering complete availability of components causes more reliability rate, so to achieve the actual behavior of PFWHS, the rate of components availability must be considered in suitable insight to designer for supply the load.
\end{abstract}

Index Terms-Optimal Sizing, Reliability Indices, Component Availability, PSO Algorithm.

\section{INTRODUCTION}

The fast process of industrialization and growing population during the past years caused the increase of electricity consumption. Limitation of space and the slow improvement of the networks also caused some areas with high load density which could result in declining of power quality and voltage collapse. At the same time, non-urban areas are witnessing poor performance of the networks like high voltage drops and high losses along the distribution lines [1]. In contrast, despite limitations in networks and available financial resources, utilities are also hardly trying to expand and boost networks. In this way, distribution generation could be one of the suitable options. One of the solutions for increasing economic efficiency in renewable power plant is using different hybrid systems. The sun and wind are two main sources in renewable energies which seem to devote a large portion of generating energy in future.

The supplied energy from these resources is predictable and as a result the power of these power plants and their storage systems will be considered much more than the amount of load power demand, to increase load reliability and availability. In hybrid systems, the generation predictability with combining the several resources is increased and in fact these resources cover each other's deficits. From this perspective wind and the sun have presented suitable overlap for each other, so the power of units and also necessary storages in combining wind-sun units compared to only wind unites or sun units have been significantly reduced.

Various definitions are presented for reliability, but the definition that is widely accepted is as follows; Reliability is the probability of a system or a component correct operation under exploitation condition in specified time [2].

Reliability calculations are major issues which should be considered along with economic and environmental evaluations resulting from using energy renewable sources. Accurate evaluation of economic profit used from these units needs investigation of rate of systems reliability. Obviously, available energy limitation in renewable energy sources and also its discontinuous behavior reduces level of system reliability [3-5].

Various methods are presented for minimization of hybrid power plant costs. Wide range of optimization methods, from classical combination like linear, nonlinear analytical and numerical programming mainly based on partial derivatives calculation to applying modern intelligent algorithms like Genetic algorithm and particle swarm optimization (PSO) are used in different researches.

In [6] a hybrid system consists of wind turbine and fuel cell is studied for improving profitability of wind power. In another study, wind farm equipped with Superconductor Magnetic Energy Storage (SMES) is studied [7]. SMES is suitable for improving power quality. In [8] hybrid system consists of solar array, fuel cell and SMES is investigated. Unit sizing determination and PV/Wind/FC hybrid system costs analysis is analyzed in [9]. In another study, 
performance and sizing of PV/Wind/FC hybrid system is considered [10]. In study [11], the method of determining optimal sizing of PV/W ind hybrid system is depicted independent from stand-alone clearly. In a similar study, capacity of diesel generator with wind turbine is optimized [12].

In this paper the effect of considering reliability indices is investigated along with economic factors for design an optimal combination for PFWHS with minimum cost and maximum of responding to load power demand. To obtain an optimal design using an intelligent algorithm seems more effective accord ing to extent of variables and magnitude of objective function. In this paper PSO algorithm is used for optimization. Also to investigating the impact of component availability rate on system under study costs and reliability due to failure and repair rate of system components and uncertainty in wind speed and solar irradiance, two scenarios are considered. In first scenario the availability of all components is considered 1 and in second scenario isn't considered 1 because of failure and repair rate of components and uncertainty in wind speed and solar irradiance.
In this paper the PFWHS modeling is presented in section II. The optimal sizing problem and the objective function are described in section III. In section IV, PSO algorith $\mathrm{m}$ is presented and in section $\mathrm{V}$, the optimization results are analyzed and finally in section VI is concluded the results.

\section{MODEL OF PFWHS}

A schematic diagram of $\mathrm{PV} / \mathrm{FC} / \mathrm{W}$ ind hybrid system (PFWHS) consists of PV array, wind turbine (WT), electrolyzer (EL), hydrogen storage tank (HST), fuel cell (FC) and inverter is shown in Fig. 1. The PV array and wind turbine work together to satisfy the load demand.When the total generated energy of the PFW HS is greater than the load demand, the extra energy will be supplied to feed the EL for hydrogen production. Also when the total generated energy of the PFWHS is lower than the load demand, the deficit energy is compensated by FC until the hydrogen of HST is depleted.

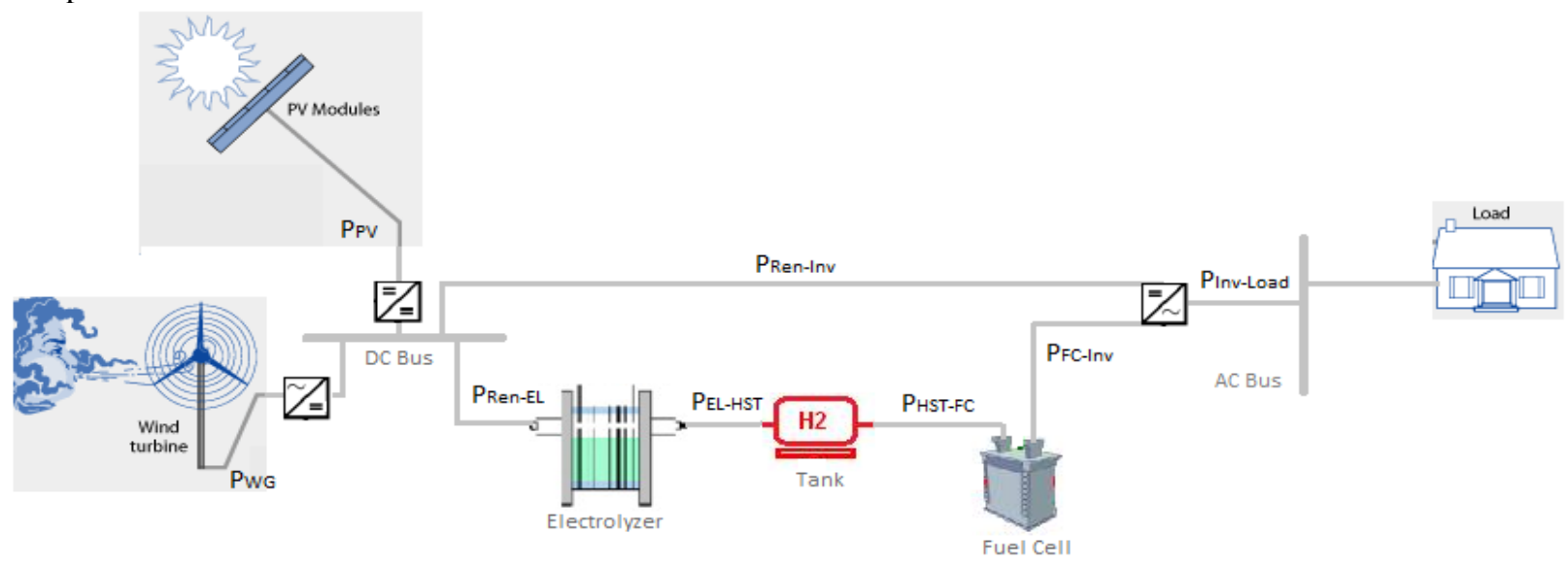

Figure 1.The schematic diagram of PV/FC/Wind hybrid system

\section{A. PV Mode}

Photovoltaic (PV) [13] converts solar radiation energy to electrical energy. PV temperature and solar radiation changes bring about changes in PV voltage level and output power as follow

$P_{P V}=0.001 G \times P_{P V, \text { rated }} \times \eta_{P V, \text { conv }}$

$G\left(t, \theta_{P V}\right)=G_{V}(t) \cos \left(\theta_{P V}\right)+G_{H}(t) \sin \left(\theta_{P V}\right)$

Where, $\mathrm{G}$ is perpendicular radiation at array's surface (W/m2), PPV,rated is rated power of each PV array at $\mathrm{G}=1000 \mathrm{~W} / \mathrm{m} 2$, and $\eta \mathrm{PV}$,conv is the efficiency of PV's DC/DC converter and Maximum Power Point Tracking System (MPPT). OPV is the PV panel tilt angle, $\mathrm{GH}(\mathrm{t})$ and $\mathrm{Gv}(\mathrm{t})$ are the horizontal and vertical components of solar irradiation. It should be noted that, temperature effects are neglected here.

\section{B. Wind Model}

The simplified model to simulate the power output of a wind turbine [14] can be defined by

$$
\begin{aligned}
& P_{W}(v)= \begin{cases}P_{R} \cdot \frac{v-{ }{ }_{C}}{v_{R}-{ }_{C}} & \left({ }{ }_{C} \leq v \leq v_{R}\right) \\
P_{R} & \left({ }{ }_{R} \leq v \leq v_{F}\right) \\
0 & \left(\begin{array}{c}
v \leq{ }_{C} \text { and } v \geq v_{F}
\end{array}\right)\end{cases} \\
& v_{W}^{h}=v_{W}^{r e f} \times\left(\frac{h}{h_{r e f}}\right)^{\alpha}
\end{aligned}
$$


Where, ${ }^{P} R$ refers to the rated power, ${ }^{v} C$ is the cut-in wind speed, ${ }^{v} R$ is the rated wind speed and ${ }^{v} F$ is the cutoff wind speed. $v_{W}^{h}$ is wind speed at a specific height, $v_{W}^{r e f}$ wind speed at the reference height (href)

\section{EL Model}

Water by EL can be decomposed into its elementary components. This process is done by passing electrical current between two electrodes that are separated by an aqueous electrolyte [15].

The energy delivered to HST from EL can be calculated as follows:

$$
P_{E L-H S T}=P_{\text {Ren-EL }} \times \eta_{E L}
$$

Where $P_{\text {Ren-EL is delivered power to EL and }} \eta_{E L \text { is }}$ efficiency of EL.

\section{HST Model}

Physical HS is one of the storage techniques that use HST to store compressed hydrogen. After compressing under high pressure, the hydrogen which is required by PEMFC is sent from the HST [16].

The stored energy in HST for each step-time can be calculated by

$$
E_{H S T}(t)=E_{H S T}(t-1)+P_{E L-H S T}(t) \Delta t-P_{H S T}-F C^{(t) \Delta t \eta} H S T
$$

Where ${ }^{P}{ }_{H S T}-F C$ is delivered power to FC from HST and ${ }^{\eta} H S T$ is HST efficiency.

The stored energy in HST can't exceed the following constraints as follows:

$$
\begin{aligned}
& E_{H S T, \text { Min }} \leq E_{H S T}(t) \leq E_{H S T, \text { Max }} \\
& E_{H S T}(t=0) \leq E_{H S T}(8760)
\end{aligned}
$$

\section{E. FC Model}

FC converts oxygen and hydrogen chemical energy to electrical energy during which some heat and water is generated as well [17]. FC output power can be defined by

$$
P_{F C-I n v}=P_{H S T-F C} \cdot \eta_{F C}
$$

Where $\eta_{F C}$ refers to efficiency of FC.

\section{F. Inverter Model}

The inverter is electrical device to convert electrical power from DC into AC form at the desired frequency of the load. The power delivered to load from inverter is calculated by

$P_{\text {Inv-Load }}=\left(P_{F C-I n v}+P_{\text {Re } n-I n v}\right) \cdot \eta_{\text {Inv }}$

Where $P_{\text {Ren-Inv is delivered power to inverter and }}$ $\eta_{\text {Inv }}$ is efficiency of inverter.

\section{OPTIMAL SIZING}

To select and optimal sizing of a PW HS to satisfy the load demand, the calculations may be carried on the reliability concept and concept of economy of power supply. In this paper the proposed methodology for PWHS calculation is based on two concepts as follow:

Technical concept (Reliability indices like:LOLE, LOLD and LPSP)

$>$ Economical concept (PFWHS cost as OCE)

The optimal configuration with the minimum OCE is selected from the set of configurations which satisfy the reliability of power supply.

\section{A. Reliability Calculation based on Indices Concept}

In this paper the applied reliability indices, can be expressed by the following equations $[18,19]$ :

Loss of load expectation can be defined by

$L O L E=\sum_{t=1}^{N} E[L O L(t)]$

Where E [LOL] refer to expectation of loss of load which is defined by

$E[L O L]=\sum_{s \in S} T_{s} \times P_{S}$

Where Tsand Ps refer to duration and probability of load loss respectively.

Loss of Energy Expectation (LOLE) can be expressed by

$L O E E=E E N S=\sum_{t=1}^{N} E[L O E(t)]$

Where $\mathrm{E}$ [LOE] is expectation of loss of energy which can be calculated as follows:

$E[L O E]=\sum_{s \in S} Q_{s} \times P_{s}$

Where Qs is amount of load loss.

The reliability of PFWHS is expressed in terms of loss of power supply probability (LPSP) which is the probability that an insufficient power supply results when the PFWHS is unable to satisfy the load demand. 
The LPSP technique is considered to be the technical implemented criteria for sizing. The LPSP of 0 means that the PFWHS power can always fully meet load demand whereas the LPSP of 1 means that the PFWHS power can't meet the load demand at all. The LPSP can be expressed as:

$$
L P S P=\frac{L O E E}{\sum_{t=1}^{N} D(t)}
$$

Where $\mathrm{D}(\mathrm{t})$ is load demand $(\mathrm{kWh})$ in time step $\mathrm{t}$. So the reliability of PFWHS can be defined by

$$
\text { Reliability }=1-L P S P
$$

The Equivalent Loss Factor is calculated by

$$
E L F=\frac{1}{N} \sum_{t=1}^{N} \frac{Q(t)}{D(t)}
$$

Where Q (t) is total load loss at step-time $\mathrm{t}$.

\section{B. Expected Generation Energy Calculation of PFWHS}

In this section the expected generation energy (EGE) of PWHS is calculated in terms of the outage probability and availability rate of per PWHS components. The expected generation energy of PWHS is defined by

$$
E G E_{\text {PFWHS }}=\sum_{n_{\text {COM }}^{\text {fail }}=0}^{N_{\text {COM }}}\left(P_{\text {PFWHS }}\left(n_{\text {COM }}^{\text {fail }}\right) \times f_{\text {PFWHS }}\left(n_{\text {COM }}^{\text {fail }}\right)\right)
$$

Where $n_{C O M}^{\text {fail }}$ is the number of components being forced outage of the grid.

Where the failure probability of PWHS can be expressed by

$$
f_{\text {PFWHS }}\left(n_{\text {COM }}^{\text {fail }}\right)=\sum\left(\begin{array}{c}
N_{\text {COM }} \\
n_{\text {COM }}^{\text {fail }}
\end{array}\right)\left(A_{\text {COM }}\right)^{N_{\text {COM }}-n_{\text {COM }}^{\text {fail }}} \times\left(1-A_{\text {COM }}\right)^{n_{\text {COM }}^{\text {fail }}}
$$

Where, $A_{\text {сом }}$ refers to availability of per PFWHS components and $P_{P F W H S}\left(n_{C O M}^{\text {fail }}\right)$ is power generated by PFWHS considering failure of components.

\section{Economical Calculation based on OCE Concept}

In this section the overall cost of energy (OCE) of PWHS takes into account the initial capital cost (CC), maintenance and repair cost (MRC), replacement cost (RC) of components as well as the associated cost to load curtailment during 20 years. The main constraint of problem is the maximum permissible level of the Equivalent Loss Factor (ELF) index.
The net preset-value cost (NPC) for a specific component can be calculated as follow $[20,21]$ :

$$
\begin{aligned}
N P C_{i}= & \left(N_{i} \times C C_{i}+N_{i} \times K_{i} \times R C_{i}\right. \\
& \left.+N_{i} \times M R C_{i} \times P W A(i r, R)\right)
\end{aligned}
$$

Where Ki and PWA(ir,R) are factors that convert replacement costs and operational costs into the net present cost, respectively. The definition of these factors is well presented in $[20,21]$.

The net-present-value cost (NPC) of load loss can be obtained by

$N P C_{\text {loss }}=L O E E \times C_{\text {loss }} \times P W A($ ir,$R)$

So the OCE can be defined as follows:

$$
O C E=\left(\sum_{i} N P C_{i}+N P C_{\text {loss }}\right)
$$

\section{Objective Function}

The objective function of optimization problem is defined by

\section{OF : Minimize OCE (23)}

The objective function should be optimized considering follow constraints:

$$
\begin{aligned}
& E[E L F] \leq E L F_{\text {max }}(24) \\
& \operatorname{Min}\left(\mathrm{N}_{\mathrm{PV}}, \mathrm{N}_{\mathrm{HST}}, \mathrm{N}_{\mathrm{WT}}\right) \geq 0 \\
& 0 \leq \theta_{\mathrm{PV}} \leq 90
\end{aligned}
$$

\section{PSO ALGORITHM}

Particle swarm is a group algorithm in which a set of particles look in problem possible space in order to find an optimum solution of objective function. Each individual moves in search space with adjustable velocity and keeps the best position gained ever in its memory. The best position obtained by all the individuals of the population is transferred between all particles [22-26]. In fact it is supposed that each particle in each moment knows about the best position obtained by all the individuals of the population until that moment. Then the general principles of the algorithm will be explained:

Considering an n-dimensional search space, and a population consisting of $\mathrm{N}$ particles, the $i^{\text {th }}$ particle is an n-dimensional vector which can be defined by (27) and the corresponding velocity of this particle is also an n-dimensional vector expressed by (28):

$X_{i}=\left[x_{i 1}, x_{i 2}, x_{i 3}, \ldots, x_{i n}\right]^{T}$ 
$V_{i}=\left[v_{i 1}, v_{i 2}, v_{i 3}, \ldots, v_{i n}\right]^{T}$

$$
\text { Where } i=1,2,3, \ldots, N
$$

In particle swarm optimization algorithm, $i^{\text {th }}$ particle saves the best position ever obtained under the name vector $P_{i}=\left[p_{i 1}, p_{i 2}, \ldots p_{i n}\right]^{T} \quad$ In its memory and $G=\left[g_{1}, g_{2}, \ldots, g_{n}\right]^{T}$ vector refers to the best position which is ever obtained by all the individuals of the population. Position of $i^{\text {th }}$ particle in $(\mathrm{t}+1)$ iteration is defined by the following equations:

$$
\begin{aligned}
& V_{i}(t+1)=\omega(t) V_{i}(t)+c_{1}(t) r_{1}\left(P_{i}(t)-X_{i}(t)\right) \\
& +c_{2}(t) r_{2}\left(G(t)-X_{i}(t)\right) \\
& X_{i}(t+1)=X_{i}(t)+\chi V_{i}(t+1)
\end{aligned}
$$

In above equation, $\omega$ refers to inertia coefficient which indicates the impact of previous velocity vector on the current iteration. $\chi$ refers to constriction factor which enters to above equations in order to limit velocity vector impact. ${ }^{c_{1}}$ and ${ }^{c_{2}}$ are cognitive parameter (local acceleration) and social parameter (Global acceleration), respectively. $r_{1}$ and $^{r_{2}}$ are random numbers, uniformly distributed with in the interval $[0,1]$.

The more product ${ }^{c_{1} \times r_{1}}$ is much larger, the $i^{\text {th }}$ particle moves more quickly toward the best position gained by it. Velocity of particle is affected under product $c_{2} \times r_{2}$ by all the individuals of population toward the best position obtained.

$\omega$ is responsible for providing desired tradeoff between the global and local search capability of the population. The bigger inertia coefficient persuades the set to search in a larger area. Now smaller inertia coefficient causes accuracy increase of set in local search. Based on obtained experiments, it is suggested that at the beginning of the search a substantial value be specified to $\omega$ (here 1 ) so that global search be in priority to local search, then in order to obtain the best possible solution, the size gradually moves toward the small size like zero.

$C_{1}$ and $C_{2}$ accelerate looking for the best local and group position, respectively. In earlier papers, these two values were considered equal to a constant value (usually 2). But further studies suggest that these two parameters also to be adjusted [26]. Experiments show that you can get the best results, in spite of adjusting ${ }^{c_{1}}$ on 2.5 at the beginning of the search and then its gradual reduction toward 0.5 . In contrast, it is better that value of $c_{2}$ also be increased on a reversed route from 0.5 to 2.5. The PSO operation is shown in Fig. 2 in $3 \mathrm{~d}$ space.

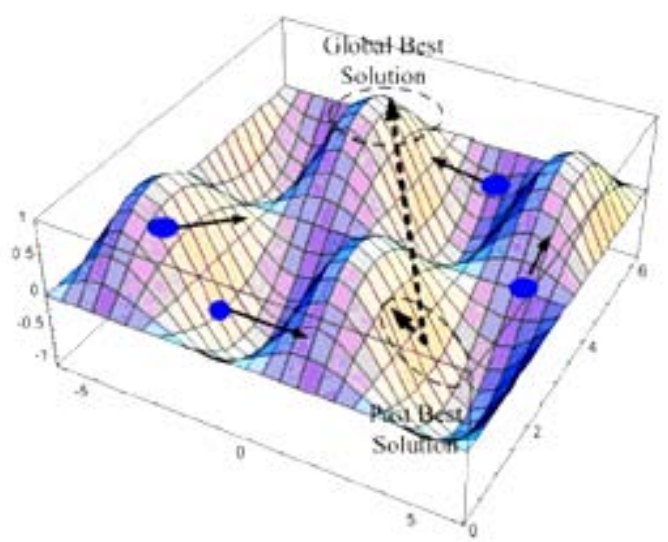

Figure 2. Defin ition of search in PSO algorith m [25]

In [27] in binary optimal problem solution and in order to prevent local optimal algorithm premature convergence, the mutation operator which is used in genetic algorithm (GA) is combined with PSO which substantially imp roves the algorithm efficiency. Despite optimization variables not being binary and according to the positive effect of mutation in last researches, this operator is also used in this paper. The philosophy of this operator is that first each variable in particle is given a random number between zero and one with normal probability distribution function (PDF). If the given number to a variable is less than the supposed value (like 0.05), then mutation operator is imposed to that variable. So, the variable is considered equal to one random value in its acceptable domain.

\section{RESULTS AND DISCUSSION}

Using PSO algorithm, case study PFWHS is optimized. Specifications of PFWHS components which their model is provided are depicted in Table 1 , and the assumptions of case study PFWHS is presented in Table 2. The applied wind and radiation datasets belong to northwest region (Jolfa, latitude: 38_56, longitude: 45_37, altitude: $710, \mathrm{~m}$ ) of Iran are shown in Figs. 3 and 4, respectively. Fig. 5 illustrates the IEEE RTS load pattern with $50 \mathrm{~kW}$ annual peak load. Load curtailment cost also is considered in case study with $5.6 \mathrm{US} \$ / \mathrm{kWh}$. 
TABLE 1. SPECIFICATION OF CASE STUDY PFWHS COMPONENTS [12]

\begin{tabular}{|c|c|c|c|c|c|c|}
\hline Device & $\begin{array}{l}\text { Investment } \\
\text { Cost } \\
\text { (US\$/unit) }\end{array}$ & $\begin{array}{c}\text { Replacement } \\
\text { Cost } \\
\text { (US\$/unit) }\end{array}$ & $\begin{array}{c}\text { Maintenance } \\
\text { and } \\
\text { Repair Cost } \\
\text { (US\$/unit-yr) }\end{array}$ & $\begin{array}{c}\text { Availability } \\
\text { (\%) }\end{array}$ & $\begin{array}{c}\text { Efficiency } \\
\text { (\%) }\end{array}$ & $\begin{array}{l}\text { Lifetime } \\
\text { (Year) }\end{array}$ \\
\hline Wind Turbine & 19400 & 15000 & 75 & 96 & - & 20 \\
\hline PV Array & 7000 & 6000 & 20 & 96 & - & 20 \\
\hline Electrolyzer & 2000 & 1500 & 25 & 100 & 75 & 20 \\
\hline Hy drogen Tank & 1300 & 1200 & 15 & 100 & 95 & 20 \\
\hline Fuel Cell & 3000 & 2500 & 175 & 100 & 50 & 5 \\
\hline ConverterDC/AC & 800 & 750 & 8 & 99.89 & 90 & 15 \\
\hline
\end{tabular}

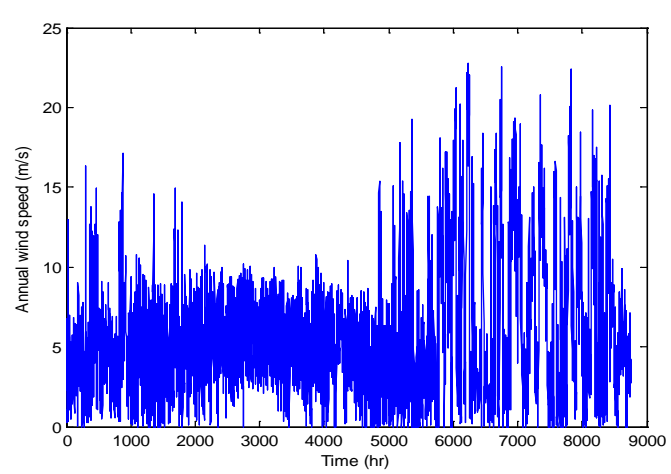

Figure 3.annualwind speed in $15 \mathrm{~m}$ heigh

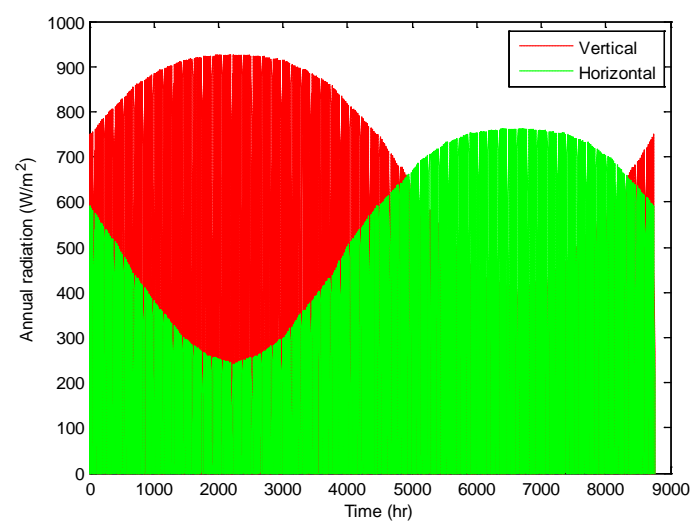

Figure 4.Annual horizontal/vertical radiation

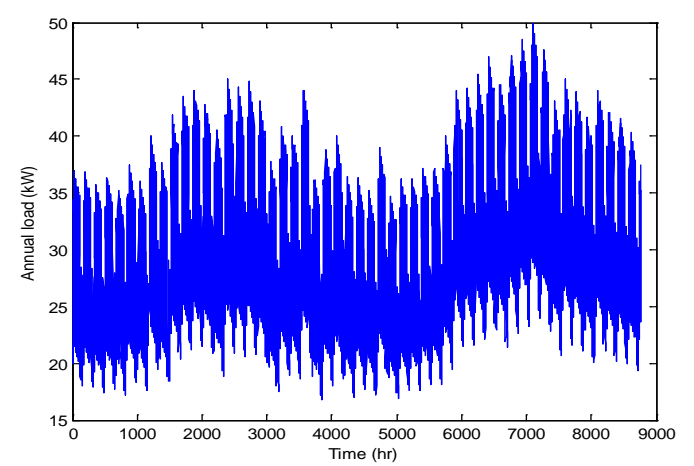

Figure 5. Curve of annual load IEEE with peak $50 \mathrm{Kw}$
The optimization results including the costs and reliability indices in two scenarios are presented in Tables 3. According to Table 3, PFWHS costs and reliability indices rate in second scenario is more than first scenario due to considering the components availability and also the PFW HS optimal sizing in first and second scenario is presented in Table 4. It is clear that the storage system due to complete availability of component, especially PV and Wind, less energy is generated in first scenario compared to second scenario considering components availability and uncertainty in wind speed and solar irradiance. Also the curve of OCE versus the reliability of PFWHS in first and second scenario is depicted in Fig. 6. As shown as in Fig. 6, the reliability rate of PFWHS is increased by increasing the OCE rate and vice versa, also the OCE rate in second scenario is more than first scenario.

The Reliability indices in first and second scenario are illustrated in Figs. 7 and 8. As it is clear that in Figs. 7 and 8, better reliability indices are resulted in first scenario compared to second scenario because of complete availability of PFWHS components. Also the expectation of stored energy in HST in two scenarios is illustrated in Figs. 9 and 10. As shown as in Figs. 9 and 10 , the stored energy rate in second scenario is more than first scenario and causes more OCE. According to obtained results, neglecting the rate of components availability in hybrid power generation systems has unsuitable results on reliability of load supply, so the rate of PFWHS components availability causes actual insight to designer for reliable and economic designing the hybrid power generation systems.

\section{TABLE2. CASE STUDY PFW HS ASSUMPTIONS}

\begin{tabular}{|l|l|l|l|l|l|}
\hline $\begin{array}{l}\text { PFWHS } \\
\text { Lifetime }\end{array}$ & $\begin{array}{l}\text { Real } \\
\text { Interest } \\
\text { Rate }\end{array}$ & $E L F_{\max }$ & $\begin{array}{l}\text { Load } \\
\text { Pattern }\end{array}$ & $\begin{array}{l}\text { Peak } \\
\text { Load }\end{array}$ & $\begin{array}{l}\text { Load } \\
\text { Curtail } \\
\text { ment } \\
\text { Cost }\end{array}$ \\
\hline $\begin{array}{l}20 \\
\text { Years }\end{array}$ & $6 \%$ & 0.01 & $\begin{array}{l}\text { IEEE } \\
\text { RTS }\end{array}$ & $\begin{array}{l}50 \\
\text { KW }\end{array}$ & $\begin{array}{l}5.6 \\
\text { US } \$ / k \\
\text { Wh }\end{array}$ \\
\hline
\end{tabular}


TABLE 3. CASE STUDY PFWHS RELIABILITY/COST EVALUATION IN FIRST AND SECOND SCENARIO

\begin{tabular}{|c|c|c|c|c|c|}
\hline $\begin{array}{c}\text { Para } \\
\mathrm{m} .\end{array}$ & $\begin{array}{c}\text { OCE } \\
\text { (MUS\$) }\end{array}$ & EIF & $\begin{array}{c}\text { LOEE } \\
(\mathrm{MWh} / \mathrm{y})\end{array}$ & $\begin{array}{c}\text { LOLE } \\
\text { (hr/yr) }\end{array}$ & $\begin{array}{c}\text { Reliabili } \\
\text { ty }\end{array}$ \\
\hline $\begin{array}{c}\text { Scen } \\
\begin{array}{c}\text { Scen } \\
\text { ario }\end{array}\end{array}$ & 2.47 & 0.0 & 2.197 & 324.1 & 0.993 \\
\hline $\begin{array}{c}\text { Seco } \\
\text { nd } \\
\text { Scen } \\
\text { ario }\end{array}$ & 2.69 & 0.0 & 2.354 & 338.8 & 0.99 \\
\hline
\end{tabular}

TABLE 4. PFW HS OPTIMAL SIZING IN CA SE STUDY PFWHS IN FIRST AND SECOND SCENARIO

\begin{tabular}{|c|c|c|c|c|c|c|c|}
\hline $\begin{array}{c}\text { Para } \\
\text { m. }\end{array}$ & $N_{W G}$ & $N_{P V}$ & $\boldsymbol{P}_{\text {el }}$ & $M_{\text {tank }}$ & $P_{F C}$ & $P_{i n v}$ & $\theta_{P V}$ \\
Scen & & & & & & & \\
\hline First & 7 & 245 & 102. & 126. & 39.5 & 47.1 & 35.8 \\
Scen & & & 6 & 7 & 9 & 0 & 0 \\
ario & & & & & & & \\
& & & & & & & \\
\hline Seco & 8 & 224 & 119. & 143. & 43.5 & 45.8 & 33.1 \\
nd & & & 5 & 6 & 0 & 3 & 1 \\
Scen & & & & & & & \\
ario & & & & & & & \\
\hline
\end{tabular}

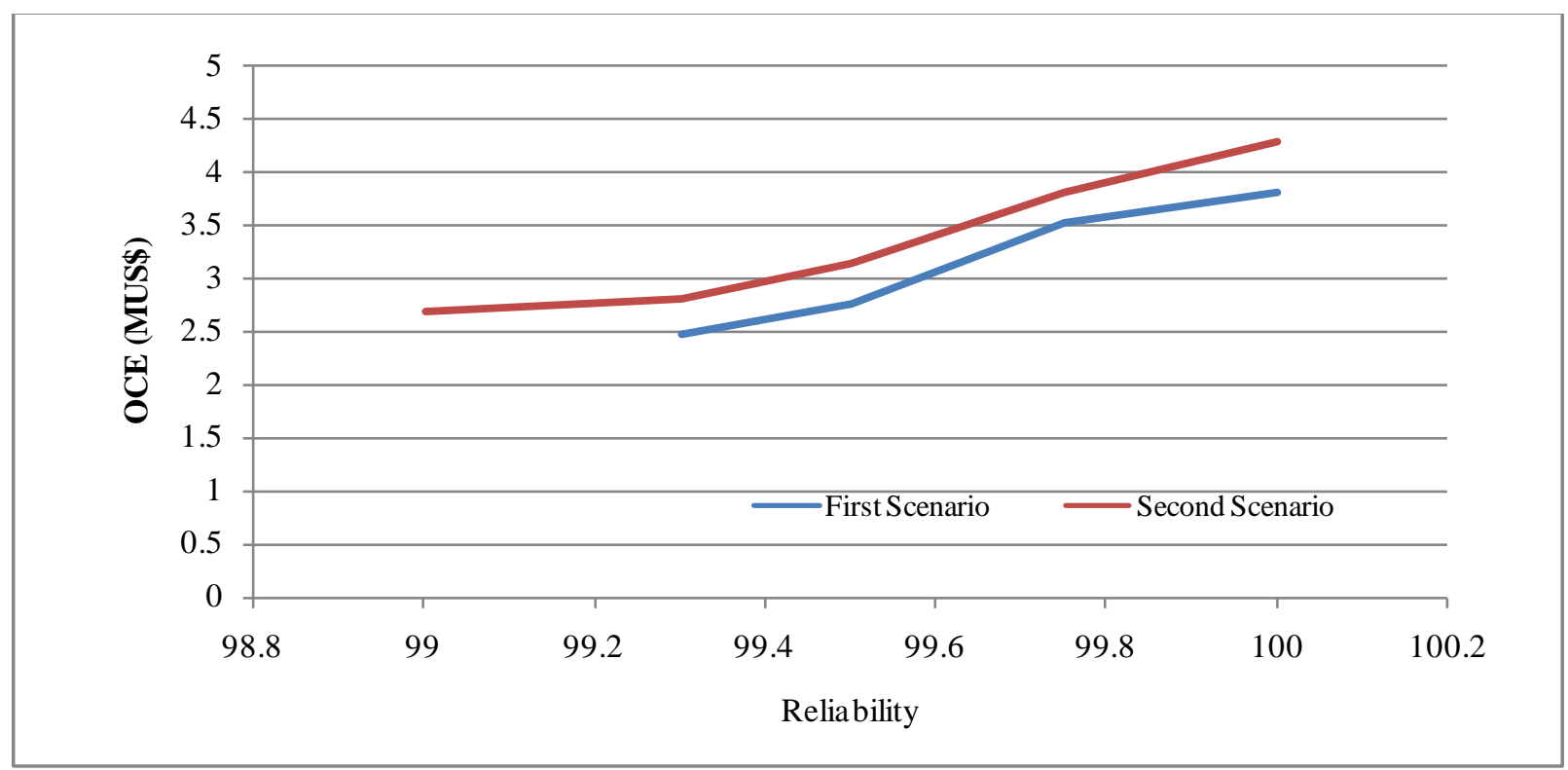

Figure 6. The OCE versus reliability in PFWHS
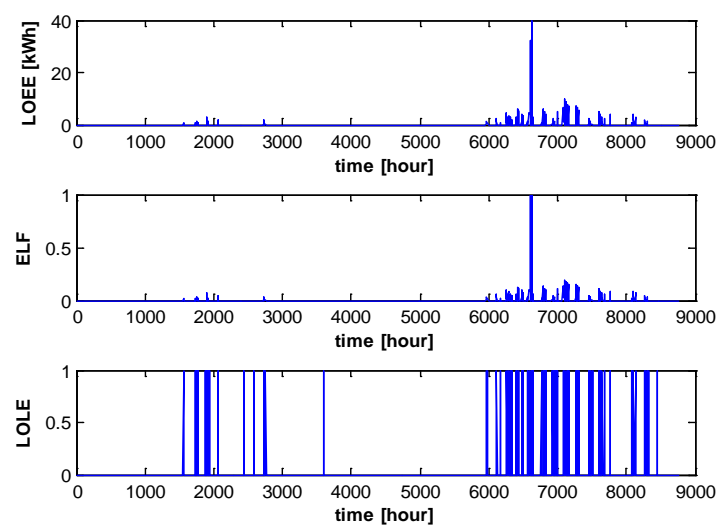

Figure 7. Reliability indices in first scenario
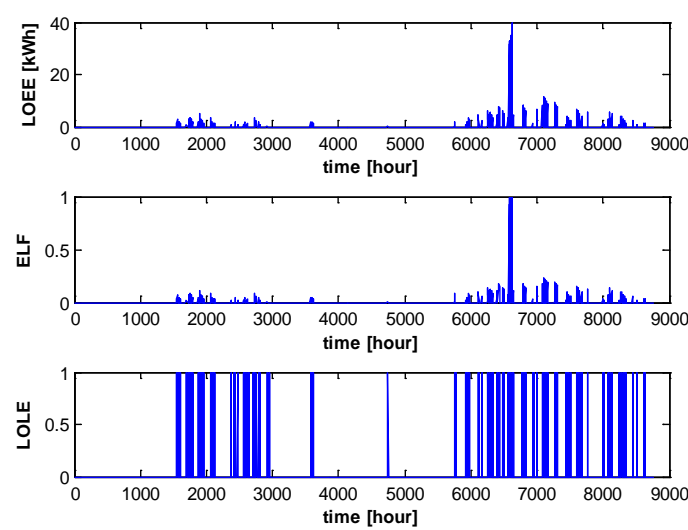

Figure 8. Reliability indices in second scenario 


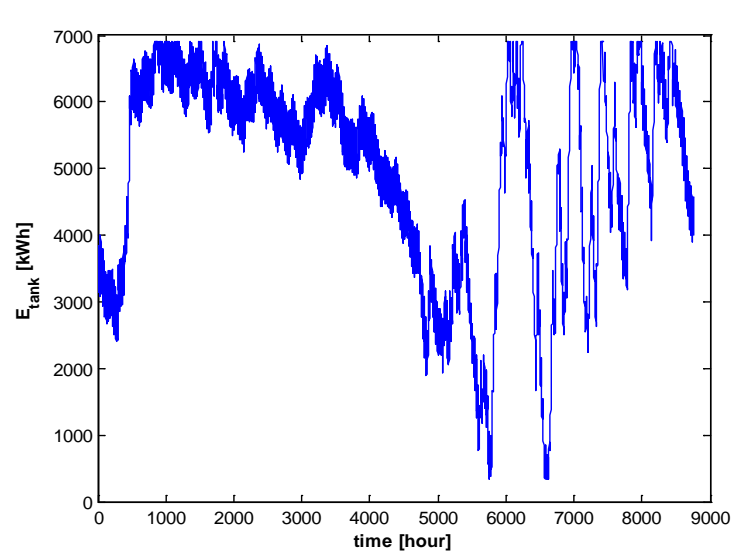

Figure 9. The expectation of stored energy in HST in first scenario

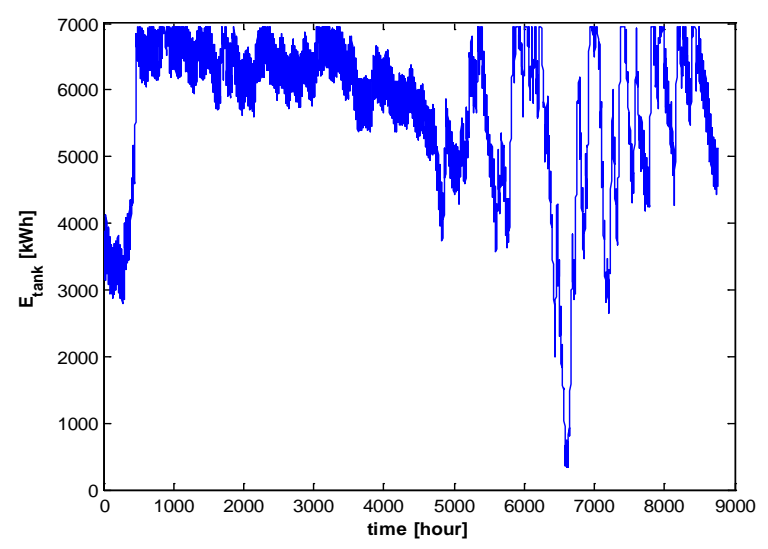

Figure 10. The expectation of stored energy in HST in second scenario

\section{CONCLUSION}

In this paper is demonstrated optimal sizing of a stand-alone PV/FC/Wind Hybrid System (PFWHS). A PSO algorithm is applied to gain optimal solution. The optimization problem is developed to determine the optimal sizing of PFWHS that can achieve the load required power supply probability (Reliability) with a minimum overall cost of energy (OCE). Also to evaluation the impact of availability of PFWHS components on optimal sizing considering technical and economical indices, two scenarios are considered. As it is clear that considering complete availability of components in first scenario causes better reliability indices compared to second scenario but this is misleading to design the PFWHS, technically and economically. According to obtained results, neglecting the rate of components availability in hybrid power generation systems has unsuitable results on reliability of load supply, so to achieve the actual behavior of PFWHS, the rate of components availability must be considered in suitable insight to designer for reliable and economic designing.

\section{REFERENCES}

[1] T.K.A. Rahman, S.R.A. Rahim, I. Musirin, 2004. Optimal Allocation and Sizing of Embedded Generators, In Proceedings of National Power and Energy Conference, Issue, 29-30, Nov. Page(s): 288-294.

[2] Bagen, R. Billinton, 2005. Evaluation of Different Operating Strategies in Small Standalone Power Systems, IEEE Transaction on Energy Conversion, Sept. Vol. 20, Issue: 3, page(s): 654-660.

[3] R. Billinton, R.N. Allan, 1992. Reliability Evaluation of Engineering Systems: Concepts and Techniques. 2nd edition, Plenum Press, New York.

[4] R. Billinton, R.N. Allan. Reliability Evaluation of Power Systems. Plenum Press, New York (1984).

[5] R. Karki, R. Billinton. Reliability/cost Implications of PV and Wind Energy Utilization in Small Isolated Power Systems, IEEE Transaction on Energy Conversion,16 (2001), pp.368-373.

[6] L. Ntziachristos, C. Kourid is, Z. Samaras, K. Pattas. A Wind-power Fuel-cell Hybrid System Study on the Non-interconnected Aegean Island Grid, Renewable Energy, 30 (2005), 1471-1487.

[7] S. Nomura, Y. Ohata, T. Hagita, H. Tsutsui, S. Tsuji-Iio, R. Shimada. Wind Farms Linked by SMES Systems, IEEE Transactions on Applied Superconductivity, (2005), pp. 1951-1954.

[8] T. Monai, I. Takano, H. Nishikawa, Y. Sawada. Response Characteristics and Operation Methods of New Type Dispersed Power Supply System Using Photovoltaic, Fuel Cell and SMES, Power Engineering Society Summer Meeting, IEEE, (2002), pp. 1231-1236.

[9] D.B. Nelson, M.H. Nehrir, C. Wang. Unit Sizing and Cost Analysis of Stand-alone Hybrid Wind/PV/fuel Cell Power Generation System, Renewable Energy, 31(2006), pp.1641-1656.

[10] S. Kim, J. Song, G. Yu. Load Sharing Operation of a $14 \mathrm{~kW}$ Photovoltaic/Wind Hybrid Power System”, Photovoltaic Specialists Conference, Conference Record of the Twenty-Sixth IEEE, (1997), pp.1325-1328.

[11] E. Koutroulis, D. Kolokotsa, A. Potirakis, K. Kalaitzakis. Methodology for Optimal Sizing of Stand-alone Photovoltaic/Wind-generator Systems using Genetic Algorithms, Solar Energy, 80(2006), pp.1072-1088.

[12] M.J. Khan, M.T. Iqbal. Pre-feasibility Study of Stand-alone Hybrid Energy Systems for Applications in Newfoundland, Renewable Energy, 30(2005), pp.835-854. 
[13] H. Yang, W. Zhou, Z. Fang,“Optimal sizing method for stand-alone hybrid solar-wind system with LPSP technology by using genetic algorithm,”Solar Energy; (2008), pp. 82:35467.

[14] Lu, L., Yang, H.X., Burnett, J. Investigation on wind power potential on Hong Kong islands - an analysis of wind power and wind turbine characteristics. Renewable Energy 27(2002), pp.1-12.

[15] L. Hedstrom, C. Wallmork, P. Alvafors "Description and Modeling of the Solar hydrogen- biogas-fuel cell System in GlashusEtt”, Journal of power sources, 131(2004), pp. 340-350.

[16] R.S. Garcia, D. Weisser. A Wind-diesel System with Hydrogen Storage: Joint Optimization of Design and Dispatch, Renewable Energy 31(2006), pp.2296-2320.

[17] Caisheng Wang et al: Dynamic Models and Model Validation for PEM Fuel Cells Using Electrical Circuits IEEE Transactions on Energy conversion, (2005).

[18] R. Billinton, R. N. Allan, Reliability Evaluation of Power Systems. 2nd ed., New York: Plenum Press, ch. 2 (1996).

[19] D. Xu, L. Kang, L. Chang, B. Cao, “Optimal sizing of standalone hybrid wind/PV power systems using genetic algorithms," in Proc. Canadian Conference on Electrical and Computer Engineering, 2005, pp. 1722-1725.

[20] S.M. Hakimi, S.M. Tafreshi, A. Kashefi. Unit Sizing of a Stand-alone Hybrid Power System Using Particle Swarm Optimization (PSO), Proceeding of the International Conference on Automation and Logistics, (2007).

[21] Lu Zhang, Georges Barakat and Adnan Yassine, "Deterministic Optimization and Cost Analysis ofHybrid PV/W ind/Battery/Diesel Power System”, INTERNATIONAL JOURNAL of RENEWABLE ENERGY RESEA RCH, 2(2012), pp. 686-696.

[22] K.E. Parasopoulos, M.N. Vrahatis. On the Computation of All Global Minimizers Through Particle Swarm optimization, IEEE Transaction on Evolutionary Computation, 8(2004).

[23] R.C. Eberhart, J. Kennedy. A new Optimizer Using Particle Swarm Theory, In Proceeding of 6th Symposium on Micro Machine and Human Science, (1995), pp. 34-44.

[24] J. Kennedy and R.C. Eberhart. Particle Swarm Optimization, In Proceeding of IEEE International Conference on Neural Networks, Perth, Australia, 4(1995), pp. 1942-1948.

[25] B. Jarboui, N. Damak, P. Siarry, A. Rebai. A Combinatorial Particle Swarm Optimization fo Solving Multi-mode Resource-constrained Project Scheduling Problems, Applied Mathematics and Computation 195(2008), pp.299-308.

[26] P.K. Tripathi, S. Bandyopadhyay, S.K. Pal. Multi-Objective Particle Swarm Optimization with Time Variant Inertia and Acceleration Coefficients, Information Sciences, 177(2007), pp.5033-5049.

[27] R.R. Tan. Hybrid Evolutionary Computation for the Development of Pollution Prevention and Control Strategies, Journal of Cleaner Production, 15(2007), 902-90.

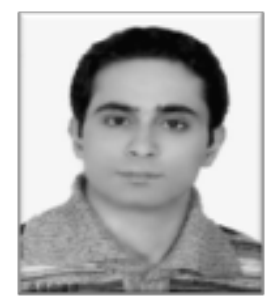

Saber ArabiNowdehwas born in Gorgan, Iran in 1980. He received the M.Sc. degree in electrical engineering from Urmia University, Urmia, Iran, in 2011. His main fields of interests are Renewable Energy, Designing and Planning of Distribution System and Reliability Assessment of Power System.

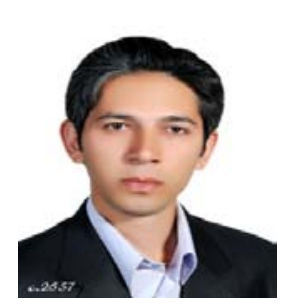

Mahdi Hajibeigy was born in Kermanshah, Iran in May 1984. He received his $B$.Sc. degree in Telecommunication Engineering in 2006 from Islamic Azad University of Urmia branch, Urmia, Iran and his M.Sc. degree in Electrical Power Engineering in March 2011 from Urmia University, Urmia, Iran. His main research interests are in Renewable Energy, advanced Power Electronics, FACTS devices and HVDC transmission systems and DC and AC active power filters. 